\section{Diabetes mellitis: risk factor for advanced liver disease}

The study by Porepa and colleagues confirms something most hepatologists have always known: diabetes mellitus is a risk factor for advanced liver disease. ${ }^{1}$ I congratulate the authors for taking on this methodologically difficult task, but they missed a few opportunities for addtional knowledge translation.

Hemochromatosis, a genetic disease of iron overload that, if not recognized, leads to diabetes and cirrhosis, should have been in the exclusion and censoring criteria. After all, the prevalence of hemochromatosis may be as high as 5/1000 people of northern European descent. $^{2}$

In addition, hepatocellular carcinoma, a known complication of cirrhosis, should have been included in the list of serious liver disease outcomes as a surrogate marker for cirrhosis because ICD (International Classification of Diseases) coding of liver disease and its complications is not always comprehensive. ${ }^{3}$ Some patients with primary liver cancer would have been included in the analysis because either cirrhosis was mentioned in the discharge abstract database or the patient underwent liver transplantation for hepatocellular carcinoma.

Obesity, diabetes and metabolic syndrome are risk factors for nonalcoholic fatty liver disease and advanced fibrosis (metabolic syndrome confers an odds ratio of 3.5 for advanced fibrosis). ${ }^{4}$ In addtion to the risk of serious liver disease in patients with diabetes alone, hypertension alone, dyslipidemia alone and obesity alone, it would have been helpful to identify, from this large population database, the additional cumulative risk for serious liver disease in patients with metabolic syndrome.

Ferhan Siddiqi MD

Lindsay Carter MD

Kevork M. Peltekian MD

Dalhousie University, Halifax, NS

\section{References}

1. Porepa L, Ray JG, Sanchez-Romeu P, et al. Newly diagnosed diabetes mellitus as a risk factor for serious liver disease. CMAJ 2010;182:E526-31.

2. McLaren GD, McLaren CE, Adams PC, et al Clinical manifestations of hemochromatosis in
HFE C282Y homozygotes identified by screening. Can J Gastroenterol 2008;22:923-30.

3. Desai S, Peltekian KM. Canadian mortality rates for liver disease: taking a closer look at ICD coding. Can J Public Health 2004;95:1098-200.

4. Adams LA, Angulo P, Lindor KD. Nonalcoholic fatty liver disease. CMAJ 2005;172:899-905.

CMAJ 2011. DOI:10.1503/cmaj.111-2029

\section{Global alcohol strategy}

In May 2010 in Geneva, the General Assembly of WHO accepted, with all votes of the 193 member states, a resolution on a global alcohol strategy. ${ }^{1}$ In it, evidence-based measures are listed that reduce the general consumption of alcohol in a given society. No need to wait any longer. ${ }^{2}$

\section{Hermann T. Meyer}

Effretikon, Switzerland

\section{References}

1. Strategies to reduce the harmful use of alcohol: draft global strategy. Geneva (Switzerland): World Health Organization; 2010. Available: www.epha .org/a/3878.

2. Flegel K, MacDonald N, Hébert PC. Binge drinking: all too prevalent and hazardous. CMAJ 2011; 183:411.

CMAJ 2011. DOI:10.1503/cmaj.111-2023

\section{Lower drug dose may improve outcomes}

I concur with the arguments made by McCormack and colleagues in support of starting medication at a very low dose. ${ }^{1}$ It has been suggested that individualized low-dose pharmacotherapy may improve outcomes in the treatment of chronic disease. ${ }^{2}$ Side effects and adverse drug reactions are substantially dose-related, and potentially there is a substantial benefit in individualized systematic titration of dosage to optimize the balance of risk and benefit. ${ }^{2}$

The strategy of using lower doses of drugs with different mechanisms of action in combination, as demonstrated in the treatment of systemic hypertension, ${ }^{3}$ provides added efficacy and nonadditive side effects. Attention to lifestyle and other contributing factors is also necessary to optimize outcomes. For example, instead of increasing the dose of statin and its potential for side effects, coronary risk is more safely reduced by combining a lower dose of statin with weight loss and antiplatelet and antihypertensive pharmacotherapy. ${ }^{2}$

There is growing evidence that lower dose drug treatment has many potential advantages and is often not less effective. This topic deserves more extensive research. It may be time to review dosing guidelines for a wide range of drugs.

\section{Simon B. Dimmitt MBBS}

Subiaco, Western Australia

\section{References}

1. McCormack JP, Allen GM, Virani AS. Is bigger better? An argument for very low starting doses. CMAJ 2011;183:65-9.

2. Dimmitt SB, Stampfer H. Low drug doses may improve outcomes in chronic disease. Med $J$ Aust 2009;191:511-3

3. Law MR, Wald NJ, Morris JK, et al. Value of low dose combination treatment with blood pressure lowering drugs: analysis of 354 randomised trials. BMJ 2003;326:1427-34

CMAJ 2011. DOI:10.1503/cmaj.111-2030

Some letters have been abbreviated for print. See www.cmaj.ca for full versions.

\title{
- Correction \\ Macrosomia and perinatal and postneonatal mortality among First Nations people in Quebec
}

In the Feb. 22 issue of $C M A J$, the title of Table 1 in the article by Wassimi and colleagues should have contained an asterisk, not a dagger symbol. ${ }^{1} C M A J$ apologizes for any inconvenience this error may have caused.

\section{Reference}

1. Wassimi S, Wilkins R, Mchugh NGL, et al. Association of macrosomia with perinatal and postneonatal mortality among First nations people in Quebec. CMAJ 2011;183:322-6.

CMAJ 2011. DOI:10.1503/cmaj.111-2026 